\section{Production of Gliotoxin by Aspergillus fumigatus mut. helvola Yuill}

IN the Research Items in NaTURE of April 29, an account is given of the production of antibiotics by Aspergillus fumigatus. To supplement this annotation we submit this short account of our own work with the mould Aspergillus fumigatus mut. helvola Yuill. An earlier publication ${ }^{1}$ has described the isolation of helvolic acid from 2-3-week cultures of this mould grown at $25^{\circ} \mathrm{C}$. on a medium containing mineral salts and 4 per cent of glucose.

Discrepancies between the antibacterial activity of the culture medium, particularly during the first few days of growth, and the yield of helvolic acid obtained, suggested the presence of a second antibacterial substance. It was found that whereas the antibacterial activity of a 20-22-day culture is scarcely diminished at all by maintaining it at $p \mathrm{H} 10$ for 5 hours at $37^{\circ} \mathrm{C}$., this treatment completely destroys the activity of 3-4-day cultures. Since helvolic acid itself is stable at $p \mathbf{H} 10$ under these conditions, it is clear that in the early stages of growth a second antibiotic, sensitive to very dilute alkali, is produced.

Investigation showed that the activity of the medium reaches a maximum after 8-9 days, then drops somewhat to reach a minimum after 16-17 days, after which it again rises to reach a fairly constant value after $20-22$ days. At this time the mould is usually harvested for the isolation of helvolic acid. To isolate the second antibiotic, 5-6 day cultures are brought to $p \mathbf{H} 10$ and immediately extracted thrice with equal volumes of chloroform, the total volume of chloroform being equal to the volume of medium being extracted. The chloroform extract is distilled under reduced pressure and the solid residue crystallized several times from hot alcohol. This process yields long colourless needles of the second antibacterial substance, the weight obtained being, roughly, $30 \mathrm{mgm}$. per litre of culture medium.

For the isolation of helvolic acid in this laboratory a magnesia column is used ${ }^{1}$ and this is eluted with hot water. Under these conditions, the alkali-sensitive material is destroyed. We have identified the second antibiotic as one already described, gliotoxin, first obtained $^{2}$ as a metabolic product of the mould Gliocladium fimbriatum Gilman and Abbott. Our identification is based primarily on the data of Johnson, Bruce and Dutcher ${ }^{3}$, who have investigated the properties of gliotoxin in considerable detail.

\begin{tabular}{|c|c|c|}
\hline Property & Gliotoxin & $\begin{array}{l}\text { Data of } \\
\text { Glister and Williams }\end{array}$ \\
\hline $\begin{array}{l}\% \text { Carbont } \\
\% \text { Hydrogen } \\
\% \text { Nitrogen } \\
\% \text { Sulphur }\end{array}$ & $\begin{array}{c}221^{\circ} \mathrm{C} \\
{[a]_{D}^{25}=-255^{\circ} \pm 15^{\circ}} \\
\left(0 \cdot 1 \% \text { in } \mathrm{CHCl}_{8}\right) \\
{[a]_{D}^{25}=-290^{\circ} \pm 10^{\circ}} \\
\left(0 \cdot 08 \% \text { in } \mathrm{C}_{2} \mathrm{H}_{5} \mathrm{OH}\right) \\
48 \cdot 08 \\
4 \cdot 96 \\
8 \cdot 15 \\
19 \cdot 29\end{array}$ & $\begin{array}{c}21 \mathcal{E}-220^{\circ} \mathrm{C} \\
{[a]_{D}^{20}=-254^{\circ}} \\
\left(0.6 \% \text { in } \mathrm{CHCl}_{3}\right) \\
\\
49 \cdot 9 \\
4 \cdot 4 \\
9 \cdot 5 \\
19 \cdot 3\end{array}$ \\
\hline
\end{tabular}

* In common with other authors we find that this value is obtained only if heating is very rapid.

t Analyses by Weiler and Strauss. Material dried at $50^{\circ} \mathrm{C}$. in vacuo.

The molecular weight determined by an X-ray method (D. Crowfoot and B. W. Rogers-Low) is $330 \pm 8$. Johnson et al. ${ }^{3}$ give 314 as their best value. The absorption spectrum, examined by Dr. E. R. Holiday, is consistent with the findings of these workers $^{3}$ that gliotoxin is an indole derivative.
The antibacterial activity of our material has been determined by Dr. M. A. Jennings, of this Department. In serial dilution tests, in which one drop of a 16-hour bacterial culture, diluted $1: 1,600$, was added to 5 c.c. quantities of nutrient broth containing diminishing amounts of gliotoxin, the minimum concentrations required to inhibit growth completely were :

$\begin{array}{lllr}\text { Staph. aureus } & \ldots & 1: 360,000 \\ \text { S. Typhi } & \ldots & \ldots & 1: 45,000 \\ \text { Bact. coli } & \ldots & \ldots & >1: 45,000\end{array}$

The sensitivity depends very much on the size of inoculum; for example, when the inoculum of Staph. aureus was increased a thousandfold, the minimum growth-inhibiting concentration was increased eightfold.

In the original publication ${ }^{1}$ on helvolic acid, reference was made to fumigacin, an antibacterial substance obtained by Waksman and his collaborators ${ }^{4}$ from Aspergillus fumigatus (Strain W84). The data then published were sufficient to establish that fumigacin and helvolic acid were not the same. In particular, fumigacin contains $3 \cdot 7$ per cent nitrogen (helvolic acid contains no nitrogen), $62 \cdot 7$ per cent carbon (helvolic acid, $69 \cdot 1$ per cent) and melts at $185-87^{\circ} \mathrm{C}$. (helvolic acid, $212^{\circ} \mathrm{C}$.). During the course of the present work, however, it has been shown $^{5}$ that fumigacin is a mixture of helvolic acid and gliotoxin. In view of this it seems rational to replace the term fumigacin, relating to a mixture of antibiotics, by the separate names gliotoxin and helvolic acid, which refer to chemical individuals. In this laboratory we have been able to obtain gliotoxin from 5-7-day cultures of a strain of Aspergillus fumigatus Fres. (Lister No. 982) kindly supplied by Dr. W. H. Wilkins, Mycology Laboratory, University Department of Botany. The mould was grown at $25^{\circ} \mathrm{C}$. on Czapek-Dox plus 2 per cent glucose.

Shortly before submitting this note for publication, it was reported that gliotoxin has been obtained from a Penicillium as yet unidentified ${ }^{6}$.

One of us (T. I. W.) is indebted to the Nuffield Fluid Research Fund for a grant towards expenses. G. A. Glister.

Sir William Dunn School of Pathology,

\section{T. I. Williams.} Oxford. May 1.

${ }^{1}$ Chain, Florey, Jennings and Williams, Brit. J. Exp. Path., 24, 108 (1943).

${ }^{2}$ Weindling and Emerson, Phytopath., 26, 1068 (1936).

${ }^{3}$ Johnson, Bruce and Dutcher, J. Amer. Chem. Soc., 65, 2005 (1943).

4 Waksman, Horning and Spencer, J. Bact., 45, 233 (1943).

s Menzel, Wintersteiner and Hoogerheide, J. Biol. Chem., 152, 419 (1944).

' Johnson, MeCrone and Bruce, J. Amer. Chem. Soc., 66, 501 (1944).

\section{X-Ray Crystallography of Gliotoxin}

We have examined a specimen of gliotoxin prepared by G. A. Glister and T. I. Williams, as above. The erystals are four- and six-sided monoclinic plates elongated along [010], and our evidence on their morphology and optic character agrees very well with the measurements of Dr. W. C. McCrone1,2.

The crystals gave good X-ray photographs from which the following data were obtained : $a=18.74 \mathrm{~A}$., $b=7.59 \mathrm{~A}$., $c=10 \cdot 36 \mathrm{~A}$., $\beta=80^{\circ}$, correct to about \pm 1 per cent; space group $P 2$. Density $=1 \cdot 543 \pm$ $0 \cdot 01$.

Since the space group requires at least two molecules in the unit cell, the crystallographic molecular 